\title{
Functional sensibility of the hand in leprosy patients
}

\author{
WIM H. VAN BRAKEL* $\ddagger$, C. MARLEEN KETS $\dagger$, \\ MONIQUE E. VAN LEERDAM $†$, \\ ISHWAR B. KHAWAS* \& KHADGA SINGH GURUNG* \\ *Green Pastures Hospital, P.O. Box 28, Pokhara, Nepal; \\ $\dagger$ Haarlemmermeerstraat 155, $1058 \mathrm{JZ}$ Amsterdam, The Netherlands
}

\section{Accepted for publication 8 July 1996}

Summary The aims of this cross-sectional comparative study was to compare the results of Semmes-Weinstein monofilament testing (SWM) and moving 2-point discrimination (M2PD) with four tests of functional sensibility: recognition of objects, discrimination of size and texture and detection of dots.

Ninety-eight leprosy in- and outpatients at Green Pastures Hospital in Pokhara, Nepal were tested with each of the above tests and the results were compared to see how well they agreed. Using the tests of functional sensibility as reference points, we examined the validity of the SWM and M2PD as predictors of functional sensibility.

There was definite, but only moderate correlation between thresholds of monofilaments and M2PD and functional sensibility of the hand. A normal result with the SWM and/or M2PD had a good predictive value for normal functional sensibility. Sensitivity was reasonable against recognition of objects and discrimination of textures as reference tests (80-90\% and 88-93\%), but poor against discrimination of size and detection of dots (50-75\% and 43-65\%). Specificity was high for most combinations of SWM or M2PD with any of the tests of functional sensibility (85-99\%). Above a monofilament threshold of $2 \mathrm{~g}$, the predictive value of an abnormal test was $100 \%$ for dot detection and $83-92 \%$ for textural discrimination. This indicates that impairment of touch sensibility at this level correlates well with loss of dot detection and textural discrimination in patients with leprous neuropathy. For M2PD the pattern was very similar. Above a threshold of $5 \mathrm{~mm}, 95-100 \%$ of affected hands had loss of dot detection and $73-80 \%$ had loss of textural discrimination.

Monofilament testing and M2PD did not seem suitable as proxy measures of functional sensibility of the hand in leprosy patients. However, a normal threshold with monofilaments and/or M2PD had a good predictive value for normal functional sensibility. Above a monofilament threshold of $2 \mathrm{~g}$ and/or a M2PD threshold of $5 \mathrm{~mm}$, textural discrimination was abnormal in most hands. 


\section{Introduction}

Impairment of neural function is considered the most serious complication of leprosy. ${ }^{1-6}$ Impairment often leads to disability and handicap of the affected person. ${ }^{3,7,8}$ These functional aspects of neural damage have received little attention. ${ }^{7}$ Different modalities of function have been studied in leprosy patients. These include nerve conduction, ${ }^{9-12}$ and autonomic vasoregulation, ${ }^{13,14}$ as well as simple methods that are suitable for use in the field, like tests for voluntary muscle power and sensory tests using nylon filaments or a ballpoint pen. ${ }^{12,15-18}$ It is claimed that thresholds for touch determined with SWM correlate well with functional sensibility of the hand and with what the patients are still able to do with their hands, ${ }^{19,20}$ the latter being the result of treatment of most practical interest to patients. However, data supporting this claim were derived from patients who did not suffer from leprosy. $^{21}$

Normal function of the hand depends on many factors including motor function, tactile sensibility, proprioception and cognition. In practice touch/pressure is often the only modality tested in cases of leprosy. ${ }^{22,23}$ We were interested in investigating the extent to which functional sensibility was affected in leprosy patients and to examine the relationship between touch sensibility and functional ability. Therefore, we compared the results of testing with Semmes-Weinstein monofilaments (SWM) and moving two-point discrimination (M2PD) with four tests of functional sensibility adapted for use in Nepal, namely recognition of objects, discrimination of size and of texture and dot detection. The aims of the study were to: 1, examine the validity of using SWM and M2PD as measures of functional sensibility in leprosy patients; and 2, investigate whether SWM and M2PD can be used as screening tests for the presence or absence of impairment of functional sensibility.

\section{Methods, concepts and definitions}

SELECTION OF PATIENTS

No particular criteria of selection or randomization were used as the objective was to compare tests in the same patient. Those tested included patients admitted to Green Pastures Hospital (GPH) for treatment of leprotic reactions and/or neural impairment (NFI) between March and May 1993 and patients attending outpatient clinics during that period. All had an established diagnosis of leprosy. Impairment of touch sensibility ranged from those in whom no loss was found to those with complete anaesthesia of both hands. If there were severe deformities or missing digits in one hand, only the contralateral one was tested.

\section{DIAGNOSIS OF LEPROSY}

The diagnosis was based on finding at least one of three cardinal clinical signs of the disease; anaesthetic skin lesions, enlarged peripheral nerve trunks or acid-fast bacilli in a split-skin smear. ${ }^{24}$ Further details of diagnosis, classification and laboratory tests, including histology have been published. ${ }^{25}$

DEFINITION OF FUNCTIONAL SENSIBILITY

Stereognosis (stereos = solid; gnosis = knowing) and functional sensibility have very similar meanings. Butterworth's Medical Dictionary defined stereognosis, as 'the ability to 
recognize the shape and characteristics of an object by means of touch. ${ }^{26}$ Collin's Dictionary of Medicine qualified characteristics as 'shape, size and texture of an object' ${ }^{27}$ However, the term is used differently in the literature of neurology and hand surgery. In the latter, stereognosis is used to denote the sensory function of the hand. In neurology the term denotes a central function that integrates a variety of sensory impulses into a particular pattern which allows someone to recognize an object. ${ }^{28,29}$ Thus, in the neurological sense, it is possible to have intact peripheral sensibility and still suffer from astereognosis. ${ }^{29}$ Because of possible confusion about the meaning of stereognosis, Moberg used the term tactile gnosis. ${ }^{30}$ In this paper we use the term functional sensibility to denote the ability to recognize and discriminate by touch and we define the term as 'the ability to explore and discriminate between and/or identify objects, including their shape, size and texture by touch'. It is similar to 'active touch' as described by Gibson. ${ }^{31}$ Existing tests of functional sensibility were adapted for use in our largely rural population and their validity was tested on healthy volunteers. ${ }^{32}$

RECOGNITION OF OBJECTS

A quantified form of this test was introduced by Moberg in $1958 .{ }^{28}$ The blindfolded patient was asked to pick up ten objects, identify them and put them in a container. The process was timed and the result expressed in seconds. Dellon modified this test to timed identification, in order to limit the effect of coexisting motor impairment. ${ }^{33}$ We introduced a further modification of omission of timing because we considered the ability to recognize objects more important than the speed with which this was achieved. The ten objects selected were similar in texture and in common use in Nepal. These were, a safety pin, small padlock, hair pin, nail, button, marble, coin, ring, bottle top and key. The test was explained, then patients were asked to identify the objects by sight to ensure that they were all familiar. Then with eyes closed, they were given each object once in a random order. The score was the number of items correctly identified.

\section{DISCRIMINATION OF SIZE}

Two sets of wooden cubes with sides measuring 1 inch, $1 \frac{1}{2}$ inches, 2 inches and $2 \frac{1}{2}$ inches were shown to the patients. After an explanation of the test they were asked to close their eyes and were presented with each of the cubes in random order and required to match them with the corresponding ones in a duplicate set. To prevent identification by differences in weight, they were not permitted to pick them up. The score was the number correctly matched.

\section{DOT DETECTION}

Originally we intended to devise a test for graphaesthesia which Butterworth's Medical Dictionary defines as 'the ability to recognize letters or figures traced on the skin by blunt pressure'. ${ }^{26}$ This is the sensory modality used in reading braille. Because many of our Nepali patients are unfamiliar with letters or geometrical shapes, the traditional test was considered inappropriate. Detection of a small dot on a smooth surface was described by Johansson and LaMotte ${ }^{34}$ and LaMotte and Whitehouse considered it 'a means of clinically testing impaired tactile sensitivity in the glabrous skin of the hand' ${ }^{35}$ Since there is no element of recognition such a test is not equivalent to graphesthesia. 
Our test object consisted of a Braille-like dot approximately $0.5 \mathrm{~mm}$ high and $0.5 \mathrm{~mm}$ wide punched in one corner of a $2 \times 2 \mathrm{~cm}$ smooth aluminium square which was glued on to a small wooden cube for ease of handling. The examiner held the block between two fingers during the test. With eyes closed, the patient was asked to identify the corner in which the dot was located, using either the index or little finger. The score for each finger was the number of correct responses out of five trials.

\section{DISCRIMINATION OF TEXTURE}

This is defined as 'the ability to discriminate between surfaces of different texture by touch' Using their finger tips humans can accurately discriminate small differences in spacing between rows and columns of small dots on a smooth surface. ${ }^{36}$ Greenspan \& LaMotte suggested that standardized textures in the form of grating patterns could be used clinically to detect impaired sensibility. ${ }^{37}$

We used five familiar materials. Smooth vinyl, 2 grades of sandpaper and 2 different textiles were glued on square wooden blocks measuring $10 \times 10 \mathrm{~cm}$. These surfaces differed little in hardness. After the test was explained, the patient closed his eyes and felt one surface with the pad of the index or little finger and then attempted to match this with one in a duplicate set. The five different textures were presented in random order to each of the two fingers. The score was the number of correct matches out of five.

\section{SEMMES-WEINSTEIN MONOFILAMENT TEST (SWM)}

Touch/pressure sensibility was tested with a standard set of five SWMs as described by BellKrotoski. ${ }^{38}$ The log numbers of these filaments were $2 \cdot 83,3 \cdot 61,4 \cdot 31,4 \cdot 56$ and $6 \cdot 65$. When applied with a force sufficient to bend the filament, these were respectively equal to application forces of $70 \mathrm{mg}, 200 \mathrm{mg}, 2 \mathrm{~g}, 4 \mathrm{~g}$ and about $280 \mathrm{~g} .{ }^{39}$ A score of 5 was given when the thinnest filament was felt and zero if the thickest one was not appreciated. The following sites were tested for the Median nerve: the volar surfaces of the terminal phalanges of the index finger and thumb and skin over the second metacarpophalangeal joint; for the Ulnar nerve: the volar surface of the terminal phalanx of the little finger, skin over the fifth metacarpophalangeal joint and proximal part of the hypothenar eminence.

\section{MOVING TWO-POINT DISCRIMINATION (M2PD)}

Moving touch sensibility for median and ulnar nerves was assessed with M2PD as recommended by Dellon. ${ }^{40}$ The test can be done with a paper clip, but we used a DiskCriminator*, a plastic disc on which metal prongs are mounted with different interprong distances. Details of the testing technique have been published. ${ }^{18}$ Only the index and little fingers were tested at the same sites used for the SWMS.

\section{DIAGNOSIS OF NEURAL IMPAIRMENT}

A score below that found in the study of normal volunteers ${ }^{33}$ was taken as evidence of neural impairment.

\footnotetext{
* Available through P.O. Box 13692, Baltimore, Maryland, 21210, USA
} 
ASSESSMENT OF NEURAL FUNCTION

SWM and M2PD tests were performed by trained physiotherapy technicians. The other tests were carried out by one or other of the authors, (MK, MvL. or IBK).

THE PURPOSES OF THE STUDY

To determine:

the specificity, sensitivity and predictive value of the results of testing with SWMs and M2PD;

the correlation between SMM/M2PD and functional sensibility; and

thresholds of SWM and M2PD tests beyond which functional sensibility is lost.

\section{STATISTICAL METHODS}

The differences between proportions was tested using the Standard Normal Deviation (SND) and McNemar's paired Chi-square test for paired sample proportions. ${ }^{41}$ The validity of the SWM and M2PD was examined using tests of functional sensibility as reference points. It is realized that these tests are not gold standards, but we consider them to be representative of functional sensibility. For these calculations the data were recoded as binary variables, using the normal level as cut-off for positive/negative. Because the data were often not normally distributed and because most were graded on ordinal, noninterval scales, the strength of association between two measures was examined by a non-parametric method, the Spearman rank correlation coefficient. A $p$-value of less than $5 \%$ was used as the level of statistical significance. The $95 \%$ confidence interval is given for proportional and correlation coefficients. Analysis was done using Epi Info Software 5.01 ${ }^{42}$ and SPSS for Windows 6.

\section{Patients}

Ninety-eight patients were examined of whom 93 (95\%) were manual workers and 74 (79\%) male. Ages ranged from 15 to 63 years (mean 40 years). The distribution of types of leprosy was as follows:

$\begin{array}{lr}\text { Tuberculoid } & 2 \\ \text { Borderline tuberculoid } & 29 \\ \text { Borderline } & 6 \\ \text { Borderline lepromatous } & 32 \\ \text { Lepromatous } & 20 \\ \text { Pure neuritic } & 4 \\ \text { Not classified } & 5\end{array}$

\section{Controls}

The results of pilot studies on these tests using volunteers from a similar rural population who had no history or evidence of leprosy or any other neurological defects have been published $^{32,44}$ and are used as controls for the present investigation. 
Table 1. Proportion of hands $(n=196)$ with impairment of sensibility as measured with different tests at different sites

\begin{tabular}{|c|c|c|c|c|c|}
\hline \multirow[b]{2}{*}{ Test/Site } & \multicolumn{2}{|c|}{ Median nerve } & \multirow[b]{2}{*}{ Site } & \multicolumn{2}{|c|}{ Ulnar nerve } \\
\hline & $\mathrm{FI}^{*}(\%)$ & $95 \% \mathrm{CI} \dagger$ & & $\mathrm{FI}^{*}(\%)$ & $95 \% \mathrm{CI} \dagger$ \\
\hline \multicolumn{6}{|l|}{ SWM $\ddagger$} \\
\hline thumb & $3 \cdot 1$ & $(0 \cdot 7-5 \cdot 5)$ & little finger & 29 & $(23-35)$ \\
\hline $\operatorname{mcp} 2 \S$ & 11 & $(5 \cdot 8-14)$ & mcp5ף & 22 & $(16-28)$ \\
\hline index finger & $7 \cdot 7$ & $(4-1)$ & hypothenar & 17 & $(12-22)$ \\
\hline median combined** & 12 & $(7-17)$ & ulnar combined** & 31 & $(25-37)$ \\
\hline \multicolumn{6}{|l|}{ M2PD†† } \\
\hline index finger & $7 \cdot 7$ & $(4-11)$ & little finger & 30 & $(24-36)$ \\
\hline Object recognition & $5 \cdot 1$ & $(2-8 \cdot 2)$ & & & \\
\hline Size discrimination & $2 \cdot 1$ & $(0 \cdot 09-4 \cdot 1)$ & & & \\
\hline \multicolumn{6}{|l|}{ Dot detection } \\
\hline index finger & 19 & $(14-24)$ & little finger & 45 & $(38-52)$ \\
\hline $\begin{array}{l}\text { Texture discrimination } \\
\text { index finger }\end{array}$ & $4 \cdot 1$ & $(1 \cdot 3-6 \cdot 9)$ & little finger & 22 & $(16-28)$ \\
\hline
\end{tabular}

* function impairment, $† 95 \%$ confidence interval, $¥$ Semmes-Weinstein monofilament test, §2nd metacarpophalangeal joint, $\mid 5$ th metacarpophalangeal joint, ** combined score for the 3 sites, which was called abnormal (= impairment) if any of the 3 sites was anaesthetic for the $200 \mathrm{mg}$ filament, $\dagger$ moving 2-point discrimination

\section{Results}

SCORES AND THRESHOLDS FOUND IN CONTROL SUBJECTS

\begin{tabular}{ll} 
The number of correctly identified objects & $9 / 10^{32}$ \\
Correct discrimination of sizes & $4 / 4^{32}$ \\
Dot detection: index finger & $4 / 5^{32}$ \\
& $3 / 5^{32}$ \\
Discrimination of textures: index finger & $4 / 5^{32}$ \\
\multicolumn{1}{c}{ little finger } & $3 / 5^{32}$ \\
Threshold for SWM (all areas tested) & $200 \mathrm{mg}^{44}$ \\
Threshold for M2PD; index finger & $4 \mathrm{~mm}^{44}$ \\
little finger & $4 \mathrm{~mm}^{44}$
\end{tabular}

\section{FINDINGS IN PATIENTS}

Analysis revealed no significant differences between right and left hands for any of the tests. We assumed that presence or absence of an association between functional and touch sensibility would be independent for the right or left hand of each patient, therefore the results are reported on the pooled sample of 196 hands.

The prevalence of neural functional impairment (NFI) by test and site is set out in Table 1. For all tests the ulnar nerve was more frequently affected than the median. There were considerable differences in results of testing with monofilaments. The thumb was affected in $3.1 \%$ of hands and the index finger in $7.7 \%$ (a difference of $4.6 \% p=0.007$, McNemar's Test). For the ulnar nerve the hypothenar area was affected in $17 \%$ of instances as compared with $29 \%$ for the little finger (a difference of $12 \%, p<0.0001$ ). 
Table 2. Relative validity of SWM testing and M2PD compared with 4 tests of functional sensibility for the median nerve $(n=196)$

\begin{tabular}{|c|c|c|c|c|c|c|}
\hline \multirow[b]{2}{*}{$\begin{array}{l}\text { Screening } \\
\text { test }\end{array}$} & \multirow[b]{2}{*}{$\begin{array}{l}\text { Reference } \\
\text { test }\end{array}$} & \multirow[b]{2}{*}{$\begin{array}{c}\text { cut-off } \\
\text { level }\end{array}$} & \multicolumn{2}{|c|}{ Predictive value $(\%)$} & \multirow[b]{2}{*}{ sensitivity (\%) } & \multirow[b]{2}{*}{ specificity (\%) } \\
\hline & & & $\begin{array}{l}\text { abnormal } \\
\text { (positive) }\end{array}$ & $\begin{array}{c}\text { normal } \\
\text { (negative) }\end{array}$ & & \\
\hline & Object recognition & & & & & \\
\hline SWM* thumb & & $200 \mathrm{mg}$ & $5 / 6 \S$ & 97 & $5 / 10 \S$ & 99 \\
\hline SWM index finger & & $200 \mathrm{mg}$ & $6 / 15$ & 98 & $6 / 10$ & 95 \\
\hline SWM median $\dagger$ & & $200 \mathrm{mg}$ & $8 / 24$ & 99 & $8 / 10$ & 91 \\
\hline \multirow[t]{2}{*}{ M2PD $\ddagger$ index finger } & & $4 \mathrm{~mm}$ & $5 / 15$ & 97 & $5 / 10$ & 94 \\
\hline & Size discrimination & & & & & \\
\hline SWM thumb & & $200 \mathrm{mg}$ & $2 / 5$ & 99 & $2 / 4$ & 98 \\
\hline SWM index finger & & $200 \mathrm{mg}$ & $2 / 14$ & 99 & $2 / 4$ & 94 \\
\hline SWM median & & $200 \mathrm{mg}$ & $2 / 22$ & 99 & $2 / 4$ & 89 \\
\hline \multirow[t]{2}{*}{ M2PD index finger } & & $4 \mathrm{~mm}$ & $1 / 15$ & 98 & $1 / 4$ & 92 \\
\hline & Dot detection & & & & & \\
\hline SWM index finger & & $200 \mathrm{mg}$ & $11 / 15$ & 86 & $11 / 37$ & 97 \\
\hline SWM median & & $200 \mathrm{mg}$ & $16 / 24$ & 88 & $16 / 37$ & 95 \\
\hline M2PD index finger & & $4 \mathrm{~mm}$ & $11 / 15$ & 86 & $11 / 37$ & 96 \\
\hline & Texture discrimination & & & & & \\
\hline SWM index finger & & $200 \mathrm{mg}$ & $6 / 14$ & 99 & $6 / 8$ & 96 \\
\hline SWM median & & $200 \mathrm{mg}$ & $6 / 13$ & 99 & $6 / 8$ & 91 \\
\hline M2PD index finger & & $4 \mathrm{~mm}$ & $7 / 15$ & 99 & $7 / 8$ & 95 \\
\hline
\end{tabular}

\footnotetext{
* Semmes-Weinstein monofilament test, $† 3$ sites combined (thumb, 2nd metacarpophalangeal joint and index finger), $\ddagger$ moving 2-point discrimination test, § When the denominator is small $(<40)$, the fraction is given instead of the percentage.
}

\section{THRESHOLDS FOR PREDICTING FUNCTIONAL STATUS}

With one possible exception, in our sample there was no clinically useful threshold for predicting abnormal discrimination of size and recognition of objects. The exception was the SWM score for the thumb. In six hands with a threshold of more than $200 \mathrm{mg}$, only one of these had normal ability to recognize objects. Above monofilament thresholds of $2 \mathrm{~g}$ (or more) dot detection was abnormal in 6/6 index fingers and 38/38 little fingers and textural discrimination was abnormal in 5/6 index fingers and 34/37 little fingers.

With M2PD thresholds above 5-mm dot detection was abnormal in 10/10 index fingers and 38/48 little fingers and textural discrimination was abnormal in 8/10 index fingers and 35/ 48 little fingers.

FUNCTIONAL SENSIBILITY AND THE MEDIAN NERVE

The agreement between the monofilament thresholds at different sites, M2PD and the tests of functional sensibility is shown in Table 2. The combined score (3 sites) for SWM gave the highest sensitivity for recognition of objects $(80 \%)$, with a specificity of $91 \%$. Spearman's correlation coefficient for this combination was $0.44(0.24-0.64)$. For the index finger the coefficient for the SWM score and dot detection was $0.5(0.34-0.66)$ and for M2PD and textural discrimination it was $0 \cdot 25(0 \cdot 10-0 \cdot 4)$.

FUNCTIONAL SENSIBILITY AND THE ULNAR NERVE

Table 3 shows the agreement between tests for the ulnar nerve. The SWM result for the little 
Table 3. Relative validity of SWM testing and M2PD compared with 4 tests of functional sensibility for the ulnar nerve $(n=196)$

\begin{tabular}{|c|c|c|c|c|c|c|}
\hline \multirow[b]{2}{*}{$\begin{array}{l}\text { Screening } \\
\text { test }\end{array}$} & \multirow[b]{2}{*}{$\begin{array}{c}\text { Reference } \\
\text { test }\end{array}$} & \multirow[b]{2}{*}{$\begin{array}{c}\text { cut-off } \\
\text { level }\end{array}$} & \multicolumn{2}{|c|}{ Predictive value $(\%)$} & \multirow[b]{2}{*}{ sensitivity (\%) } & \multirow[b]{2}{*}{ specificity (\%) } \\
\hline & & & $\begin{array}{l}\text { abnormal } \\
\text { (positive) }\end{array}$ & $\begin{array}{c}\text { normal } \\
\text { (negative) }\end{array}$ & & \\
\hline & Object recognition & & & & & \\
\hline SWM* little finger & & $200 \mathrm{mg}$ & 16 & 99 & $9 / 10 \S$ & 75 \\
\hline SWM ulnar $\dagger$ & & $200 \mathrm{mg}$ & 15 & 99 & $9 / 10$ & 73 \\
\hline \multirow[t]{2}{*}{ M2PD $\ddagger$ little finger } & & $4 \mathrm{~mm}$ & 11 & 97 & $7 / 10$ & 72 \\
\hline & Size discrimination & & & & & \\
\hline SWM little finger & & $200 \mathrm{mg}$ & $3 \cdot 6$ & 99 & $2 / 4$ & 72 \\
\hline SWM ulnar & & $200 \mathrm{mg}$ & $3 \cdot 4$ & 99 & $2 / 4$ & 70 \\
\hline \multirow[t]{2}{*}{ M2PD little finger } & & $4 \mathrm{~mm}$ & $5 \cdot 1$ & 99 & $3 / 4$ & 70 \\
\hline & Dot detection & & & & & \\
\hline SWM little finger & & $200 \mathrm{mg}$ & 96 & 75 & 60 & 98 \\
\hline SWM ulnar & & $200 \mathrm{mg}$ & 97 & 77 & 65 & 98 \\
\hline M2PD little finger & & $4 \mathrm{~mm}$ & 84 & 75 & 60 & 92 \\
\hline & Texture discrimination & & & & & \\
\hline SWM little finger & & $200 \mathrm{mg}$ & 70 & 96 & 88 & 89 \\
\hline SWM ulnar & & $200 \mathrm{mg}$ & 69 & 98 & 93 & 88 \\
\hline M2PD little finger & & $4 \mathrm{~mm}$ & 60 & 96 & 88 & 85 \\
\hline
\end{tabular}

* Semmes-Weinstein monofilament test, $† 3$ sites combined (little finger, 5th metacarpophalangeal joint and hypothenar), ‡moving 2-point discrimination test, $\S$ When the denominator is small $(<40)$, the fraction is given instead of the percentage.

finger agreed well with score for recognition of objects, Spearman's correlation coefficient was $0 \cdot 35(0 \cdot 21-0 \cdot 49)$. The correlation coefficients for the combination of the combined SWM score and dot detection and for the little finger and dot detection were both high, being 0.77 $(0.7-0.84)$ and $0.73(0.66-0.8)$ respectively. There was good agreement between the ulnar SWM and M2PD scores and textural discrimination. The correclation coefficient for the combination of the SWM score and textural discrimination was $0.69(0.59-0.79)$.

\section{Discussion}

Some investigators claim a close correlation between hand function and testing with monofilaments ${ }^{21,43}$ whilst this is denied by others. ${ }^{33,45}$ According to Moberg and Dellon the tests which correlate best with functional sensibility are static and moving 2PD. ${ }^{28,33,46}$ Previously we found a good correlation between the results of SWM and M2PD in sensory assessment of leprosy patients. ${ }^{18}$ Although the present study shows no strong correlation between scores for touch sensibility and the result of tests for functional sensibility, there is evidence that critical cutoff thresholds for SWM and M2PD tests can be used as predictors of functional sensibility.

\section{RECOGNITION OF OBJECTS}

This test represents function of the hand more comprehensively than the other ones because it combines graphaesthesia, discrimination of size and texture and motor activity which also 
involves receptors in muscles, tendons and joints. Therefore it could be seen as a stand alone test for functional sensibility of the hand. Citon and Taylor considered a timed functional recognition test to be a 'reliable and reproducible test of sensory function' in patients with peripheral nerve injuries. ${ }^{47}$ In our study only 10/196 hands had impairment of this complex function, which was not affected earlier than the more simple discrimination of textures and detection of touch. Previously we found that impairment of proprioception was uncommon in leprosy patients. ${ }^{18}$

Surprisingly, sensitivity values for this test were higher for the ulnar than the median nerve, although manipulation was mainly done between the thumb and index finger. However, this finding may not be reliable owing to the small number of hands with abnormal scores. The predictive value of normal thresholds for SWM and M2PD tests was high, indicating that such patients would be likely to have unimpaired ability to recognize objects.

Dellon and Kallman used a timed-object recognition test to measure functional sensibility in 18 patients with lesions due to in jury or compression of nerves. ${ }^{46} \mathrm{M} 2 \mathrm{PD}$ correlated better with the number of objects identified than pressure measured with SWM (Pearson's $r=0 \cdot 87$ vs 0.45 ). Novak et al. evaluated a test similar to ours (but with 8 objects). ${ }^{45}$ Reliability between 2 testers was very high (intraclass correlation coefficient $[\mathrm{ICC}]=0 \cdot 99$ ). Correlation between results of this test and M2PD was close, with a Spearman Correlation coefficient of 0.76. Correlation with monofilament threshold was lower (correlation coefficient 0.69). In the present study correlation was better between functional sensibility and SWM results than between the former and M2PD. Thus it seems that the relationship between impairment of touch sensibility and recognition of objects varies with the nature of the lesion in the nerve. It must be stressed that in leprosy lesions are not necessarily homogeneous throughout the nerves.

\section{DOT DETECTION}

Johansson \& LaMotte showed that humans with intact cutaneous sensibility can detect raised elements of only about $3 \mu$ high and $230 \mu$ in diameter on a smooth surface. ${ }^{34}$ Movement of the finger tip was essential for detection. Rapidly adapting mechanoreceptors were found to have the lowest thresholds for detection, ${ }^{35}$ but when larger dots were used, other mechanoreceptive afferents were also stimulated. ${ }^{35}$ In our test a very much larger dot was used. The results were abnormal in most patients with an abnormal SWM or M2PD threshold, but the range of results in those with normal touch thresholds was wide. This might mean that it was a more sensitive test for sensory impairment, but such a conclusion needs confirmation by a battery of tests including one with a controlled stimulus, like vibrometery.

Recently Novak et al. reported a 'new measure of fine sensory function, the braille pattern identification test. ${ }^{48}$ Instead of a single dot, as in our test, they used several patterns in matrices of $3 \times 3$. This test involves recognition and is a test of graphaestesia. They found good correlation between it and static and moving 2-point discrimination with an interclass correlation coefficient [ICC] of around 0.75 . Correlation with vibration and SWM was slightly less good (ICC around 0.65). Porter found a good correlation between his test of recognition of letters, 2-point discrimination and Moberg's pick-up test. ${ }^{49}$ Moving 2-point discrimination seems to correlate well with tests involving an element of recognition such as recognition of objects and classical tests of graphaesthesia. As we removed the element of recognition from our tests, this may explain the lack of correlation we found between M2PD and dot detection. 


\section{DISCRIMINATION OF TEXTURE}

The ability to detect differences in roughness is mediated by SAI and RAI cutaneous mechanoreceptors. ${ }^{36,50}$ Given normal cognition and intact proximal neural pathways, textural discrimination is a test of the integrity of the thick myelinated afferents. It is therefore not surprising that the results of this test correlated well with SWM thresholds and M2PD. Sensitivity and specificity of the two latter were high. Finding normal touch sensibility was predictive of unimpaired textural discrimination. The results of textural discrimination correlated more closely SWM thresholds than with M2PD (Spearman's correlation coefficient 0.70 vs $0 \cdot 59$ ).

Novak et al. ${ }^{45}$ evaluated reliability of textural identification in 30 patients who were asked to order five cards ranging in texture from smooth to rough. Time and order of response were considered. The interclass correlation coefficient between two testers was good (ICC 0.77). They also examined the correlation between textural identification, monofilament testing and M2PD. The Spearman correlation coefficient for textural identification vs monofilament testing was -0.31 or -0.44 , depending on the examiner. For textural identification vs M2PD the coefficients were -0.33 and -0.53 .

\section{THRESHOLDS FOR PREDICTING ABNORMAL FUNCTIONAL SENSIBILITY}

No clinically significant thresholds could be identified as predicting impairment of recognition of objects and discrimination of sizes. This was partly due to the high number of patients scoring normally in these tests. For dot detection and textural discrimination the pattern was consistent. An SWM threshold above $2 \mathrm{~g}$ was $100 \%$ predictive of an abnormal test for dot detection and $83-93 \%$ for discrimination of textures. This monofilament threshold is said to correspond with protective sensibility in the hand. ${ }^{21}$ Possibly loss of protective sensation in the hand is associated with defective dot detection and textural discrimination in leprous neuropathy. In most affected hands with a threshold above $5 \mathrm{~mm}$ for $\mathrm{M} 2 \mathrm{PD}$, dot detection and textural discrimination were impaired. For this threshold the predictive value of an abnormal test was $73-80 \%$. However, the predictive value of a test is dependent on the prevalence of the condition that is measured. ${ }^{51}$ Where the prevalence of neural impairment is lower than in the present study, proportionally more patients will test false positive and therefore the predictive value of a positive (abnormal) test will be lower.

Our results based on testing isolated areas, suggest that in leprous neuropathy, there is only a moderate correlation between monofilament or M2PD test results and functional sensibility. There may be three explanations of our findings.

First, touch/pressure sensibility and M2PD may not be suitable alternative tests for functional sensibility. Actively exploring fingers stimulate all available receptors including mechanoreceptors in muscles and joints which generate impulses providing additional information about the object being touched. Unless all afferent fibres are affected homogeneously, which is not the case in leprosy ${ }^{52}$ a close correlation between thresholds for touch and functional sensibility cannot be expected.

Second, the four tests employed may not be valid and reliable enough as measures of functional sensibility. No reference tests for functional sensibility were available against which ours could be validated. Tests assessing manual function that are in common use in rehabilitation and occupational therapy assessments in developed countries include the Jebsen hand function test, the Williams board test and Moberg's precision sensory tests grips. ${ }^{53-55}$ In their present form none of these tests is suitable for use as a reference test in Nepal. 
Third, the range of impairment in our sample could be considered inadequate. With a prevalence of median and ulnar sensory impairment of $12 \%$ and $31 \%$ (SMW) most patients were expected to have normal functional sensibility. Only $1.5 \%$ of median nerve and $3.6 \%$ of ulnar nerves in our sample of patients had complete loss of touch sensibility. Therefore it could be argued that the number of cases with severe nerve damage was insufficient to fully examine the relationship between SWM, M2PD and tests of functional sensibility. Outside referral centres one usually deals with populations that have a lower prevalence of neuropathy than ours. Therefore our findings may represent the operational relationship between tests.

In our experience, the consequences of impairment of sensibility are inadequately appreciated by many leprosy workers. Our understanding of the sensory neuropathy in leprosy and its epidemiology and treatment is still only partial. Much further work is needed on functional assessment of hands and feet, and prevention and treatment of neuropathy. However limited our knowledge or resources may be, much harm can be prevented if physicians and health workers dealing with leprosy patients made regular use of available methods of assessing neural function and treated neuropathies and their consequences promptly.

\section{Conclusions}

Semmes-Weinstein monofilament testing and moving 2-point discrimination seem to be unsuitable substitutes for testing functional sensibility of hands in leprosy patients.

A normal threshold for SWM and/or M2PD has a good predictive value for normal functional sensibility.

With a monofilament threshold above $2 \mathrm{~g}$ and/or a M2PD threshold of $5 \mathrm{~mm}$ most hands had abnormal textural discrimination. These results support the validity of the SWM and $\mathrm{M} 2 \mathrm{PD}$ as screening tests for impairment of tactile sensibility in leprosy patients.

\section{Acknowledgments}

The authors wish to thank Dr Yolanda van der Graaf and Professor Dr G. I. Jennekens for constructive criticism of a previous draft of the manuscript. We are indebted to the staff of the Physiotherapy Department at Green Pastures Hospital who spend much of their time performing detailed functional assessments, on which this study is based. The work at Green Pastures Hospital is dedicated to the service and glory of God.

\section{References}

${ }^{1}$ Ridley DS, Job CK. The pathology of leprosy. In: Hastings RC. (ed) Leprosy. Churchill Livingstone, Edinburgh, 1985.

2 Job CK. Nerve damage in leprosy. Int J Lepr 1989; 57: 532-9.

3 Srinivasan H. Prevention of disabilities in patients with leprosy. A practical guide. World Health Organisation, Geneva, 1993.

4 Watson JM. Essential action to minimise disability in leprosy patients. The Leprosy Mission International. Stanley L. Hunt (Printers) Ltd, 1988.

5 Becx-Bleumink M, Berhe D, 'T Mannetje W. The management of nerve damage in the leprosy control services. Lepr Rev 1990; 61: 1-11. 
${ }^{6}$ Rose P, Waters MFR. Reversal Reactions in leprosy and their management. Lepr Rev 1991; 62: 113-21.

7 Brandsma JW, Heerkens YF, Lakerveld-Heyl K, Mischner-van Ravensberg CD. The international classification of impairments, disabilities and handicaps in leprosy-control projects. Lepr Rev 1992; 63: 337-44.

${ }^{8}$ Coleman WC, Madrigal DR. The patient with sensory loss. Int J Lepr 1985; 53(2): 255-7.

9 Magora A, Sheskin J, Sagher F, Gonen B. The condition of the peripheral nerve in leprosy under various forms of treatment. Int J Lepr 1970; 38: 149-63.

10 Verghese M, Ittimani KV, Satyanaran KR, Mathai R, Bhakthaviriam C. A study of the conduction velocity of the motor fibres of the ulnar and median nerves in leprosy. Int J Lepr 1970; 38: 271.

11 McLeod JG, Hargrave JC, Walsh JC, Booth GC, Gye RS, Barron A. Nerve conduction studies in leprosy. Int J Lepr 1975; 43: 21-31.

12 Naafs B, Dagne T. Sensory testing: a sensitive method in the follow-up of nerve involvement. Int J Lepr 1977; 45: 364-8.

13 Abbot NC, Beck JS, Samson PD, Butlin CR, Brown RA, Forster A, Grange JM, Cree IA. Impairment of fingertip vasomotor reflexes in leprosy patients and apparently healthy contacts. Int J Lepr 1991; 59: 537-47.

14 Abbot NC, Beck JS, Samson PD, Butlin CR, Bennett PJ, Grange JM. Cold fingers in leprosy. Int J Lepr 1992; 60: 580-6.

15 Birke JA, Sims DS. Plantar sensory threshold in the ulcerative foot. Lepr Rev 1986; 57: 261-7.

16 Watson JM. Disability control in a leprosy control programme. Lepr Rev 1989; 60: 169-77.

17 Palande DD, Bowden REM. Early detection of damage to nerves in leprosy. Lepr Rev 1992; 63: 60-72.

18 van Brakel WH, Shute J, Dixon JA, Arzet H. Evaluation of sensibility in leprosy-comparison of various clinical methods. Lepr Rev 1994; 65: 106-21.

19 Bell-Krotoski JA. Hand screen for early detection and monitoring of peripheral neuropathy part II. The Star 1992; 51(3): 3-7.

20 Breger D. Correlating Semmes-Weinstein monofilament mappings with sensory nerve conduction parameters in Hansen's disease patients: an update. J Hand Ther 1987; Oct-Dec: 33-7.

${ }^{21}$ Bell-Krotoski JA. Light touch-deep pressure testing using Semmes-Weinstein monofilaments. In: Rehabilitation of the hand, 3rd ed. Hunter et al. (eds) C.V. Mosby Co., 1989; 585-93.

22 Prevention of disability. Guidelines for leprosy control programmes. ILEP, London, 1993.

23 Jennekens FGI, Jennekens-Schinkel A. Neurological examination of patients suffering from leprosy: is it worthwhile? Lepr Rev 1992; 63: 269-76.

24 Pfaltzgraff RE, Bryceson A. Clinical leprosy. In: Hastings RC. (ed), Leprosy. Edinburgh: Churchill Livingstone, 1985: p. 136-7.

25 van Brakel WH, de Soldenhoff R, McDougall AC. The allocation of leprosy patients into paucibacillary and multibacillary groups for multidrug therapy, taking into account the number of body areas affected by skin, or skin and nerve lesions. Lepr Rev 1992; 63: 231-45.

26 Butterworths Medical Dictionary. Critchley M (chief ed.), Butterworths \& Co (Publ), London, 1984.

27 Collins Dictionary of Medicine. Youngson RM, HarperCollins (Publ), Glasgow, 1992.

28 Moberg E. Objective methods of determining functional value of sensibility in the hand. J Bone Jt Surg (B) 1958; 40: 454-66.

29 Luria AR. Higher cortical functions in man. Basic Books, Inc, Publishers, Cambridge (Mass.), 1965.

30 Moberg E. Criticism and study of methods for examining sensibility in the hand. Neurology 1962; 12: 8-19.

31 Gibson JJ. Observations on active touch. Psychol Rev 1962; 69: 477-91.

32 van Brakel. Peripheral neuropathy in leprosy - the continuing challenge. Doctorate thesis, University of Utrecht, 1994.

33 Dellon AL. Evaluation of sensibility and re-education of sensation in the hand. Baltimore: John D. Lucas Printing Co, 1988.

34 Johansson RS, LaMotte RH. Tactile detection thresholds for a single asperity on an otherwise smooth surface. Somatosens Res 1983; 1: 21-31.

35 LaMotte RH, Whitehouse J. Tactile detection of a dot on a smooth surface: peripheral neural events. J Neurophys 1986; 56: 1109-28.

36 Connor CE, Johnson KO. Neural coding of tactile texture: comparison of spatial and temporal mechanisms for roughness perception. J Neurosc 1992; 12: 3414-26.

37 Greenspan JD, LaMotte RH. Cutaneous mechanoreceptors of the hand: experimental studies and their implications for clinical testing of tactile sensation. J Hand Ther 1993; Apri-June: 75-82.

38 Bell-Krotoski JA. 'Pocket' filaments and specifications for the Semmes-Weinstein Monofilaments. J Hand Ther, 1990; Jan-Mar: 26-31.

39 Bell-Krotoski JA, Tomancik E. The repeatability of testing with Semmes Weinstein Monofilaments. J Hand Surg, 1987; 12A: 155-61.

40 Dellon AL. The moving two-point discrimination test: clinical evaluation of the quickly adapting fiber/receptor system. J Hand Surg, 1978 3: 474.

41 Armitage P, Berry G. Statistical Methods in Medical Research. 2nd ed. Oxford: Blackwell Scientific Publications, 1987: 121-4. 
42 Dean AG, Dean JA, Dicker RC. Epi Info. Version 5: a word processing, database and statistics program for epidemiology on microcomputers. USD, Inc., Stone Mountain, Georgia, 1990.

43 Bell-Krotoski JA, Weinstein S, Weinstein C. Testing sensibility, including touch-pressure, two-point discrimination, point localization and vibration. J Hand Ther 1993; Apr-June: 114-23.

44 Kets M, van Leerdam M, van Brakel WH, Khawas IB, Gurung KS. Reference values touch sensibility thresholds in healthy Nepalese volunteers. Lepr Rev 1996; 67: 28-38.

45 Novak CB, Mackinnon SE, Williams JI, Kelly I. Establishment of reliability in the evaluation of hand sensibility. Plast Recon Surg 1993; 92(2): 311-22.

46 Dellon AL, Kallman CH. Evaluation of functional sensation in the hand. J Hand Surg (A), 1983; 8: 865-70.

47 Citron N, Taylor J. Tendon transfer in partially anaesthetic hands. J Hand Surg 1987; 12-B: 14-8.

48 Novak CB, Mackinnon SE, Williams JI, Kelly L. Development of a new measure of new sensory function. Plast Recon Surg 1993; 92(2): 301-10.

49 Porter RW. New test for finger-tip sensation. Br Med J 1966; 2: 927-8.

50 Phillips JR, Johansson RS, Johnson KO. Responses of human mechanoreceptive afferents to embossed dot arrays scanned across fingerpad skin. J Neurosc 1992; 12: 827-39.

51 Hennekens CH, Buring JE. Epidemiology in medicine. Mayrent SL. (ed). Little, Brown and Co., Boston, 1987; pp. $336 \mathrm{ff}$.

52 Jacobs JM, Shetty VP, Antia NH. Teased fibre studies in leprous neuropathy. J Neurol Sci 1987; 79: 301-13.

${ }^{53}$ Hackel ME, Wolfe GA, Bang SM, Canfield JS. Changes in hand function in the aging adult as determined by the Jebsen test of hand function. Phys Ther 1992; 72: 373-7.

54 Falconer J, Hughes SL, Naughton BJ, Singer R, Chang RW, Sinacore JM. Self report and performance-based hand function tests as correlates of dependancy in the elderly. J Am Geriatr Soc 1991; 39: 656-9.

55 Moberg E. Criticism and study of methods for examining sensibility in the hand. Neurology 1962; 12: 8-19. 